\title{
Thermal effects on the mechanical behavior of Paris green clay- concrete interface
}

\author{
Kexin Yin ${ }^{1,2}$, Roxana Vasilescu ${ }^{3}$, Anne-Laure Fauchille ${ }^{2}$ and Panagiotis Kotronis ${ }^{2}$ \\ ${ }^{1}$ Department of Civil Engineering, Nanjing University of Aeronautics and Astronautics, Nanjing, 210016, PR China \\ ${ }^{2}$ Institut de Recherche en Génie Civil et Mécanique (GeM), Ecole Centrale de Nantes, UMR 6183 CNRS, 1 rue de la Noë 44321 Nantes \\ Cedex 3, France \\ ${ }^{3}$ PINTO SAS, 48 Rue Jules Verne, 35300, Fougères, France
}

\section{Introduction}

Energy piles are dual purpose foundation elements that are used both to transfer the building loads to the supporting soil and as heat exchangers (heating/cooling). Over the seasons, these piles are subjected to heating and cooling cycles that result in cyclic expansion and contraction. The expansion and contraction bring about the increase of vertical displacements and the modification of vertical stress on the piles. In other words, the thermomechanical behavior of the pile, the soil, and the soil-pile interface changes. Despite the increasing number of studies on energy piles in recent years, the impact of thermomechanical cycles on the behavior of soil and the soil-pile interface is still poorly documented (Y in 2021; Yin et al. 2021a).

To assess the impact of thermal cycles on the mobilization of the shear strength of the interface between energy piles and clayey soils, a series of direct shear tests on Paris green clay-concrete interfaces was performed in the laboratory using a new device adapted to thermomechanical loadings. The machine was validated and employed to perform soil-structure interface direct shear tests under various thermomechanical loadings (Vasilescu et al. 2018; Vasilescu et al. 2019; Vasilescu 2019; Yin 2021; Yin et al. 2021b). The upper part of the shear box is used to contain a green clay sample with a size of $100 \mathrm{~mm} \times 100 \mathrm{~mm} \times 50 \mathrm{~mm}$. The bottom part is designed to hold a concrete plate having dimensions of $140 \mathrm{~mm} \times 100 \mathrm{~mm} \times 11 \mathrm{~mm}$. The machine can carry out displacement- or load-controlled shear tests. More details about the direct shear device can be seen in Vasilescu (2019) and Yin (2021).

The soil used in this study is Romainville green clay, which was sampled from the in-situ testing site in École Nationale des Ponts et Chaussées (Parisian area, France). $92 \%$ of the green clay particles have a diameter smaller than $80 \mu \mathrm{m}$ (Mantho 2005, Vasilescu 2019). The green clay's liquid limit (wL) and plastic limit (wL) are $95 \%$ and $31 \%$, respectively. In the laboratory, the green clay was cut from the borehole tube and dried in an oven at a temperature of $105^{\circ} \mathrm{C}$ for at least 48 hours. When preparing samples for the interface direct shear tests, the dry green clay was mixed into slurry with distilled water at $1.5 \mathrm{wL}$, then moved to a designed oedometer cell (diameter $=150 \mathrm{~mm})$ to perform a preconsolidation process (see Yin (2021) and Yin et al. (2021c)). The maximum vertical stress during preconsolidation was 50 $\mathrm{kPa}$. After the preconsolidation phase the sample was cut into a square shape by a trimming tool (see Yin (2021) and Yin et al. (2021c)) for the interface direct shear box. This procedure of sample preparation guarantees the fabrication of green clay specimens with homogeneous structure for the interface tests (Yin et al. 2019; Yin 2021; Yin et al. 2021c; Yin et al. 2021d; Yin et al. 2021e). A concrete plate was cut from a concrete block and used for all the interface tests. The Ra and Rmax of the concrete plate are $10.2 \mu \mathrm{m}$ and $90.5 \mu \mathrm{m}$, respectively. The normalized roughness, $\mathrm{Rn}$, is $>90.5$, therefore in this case the interface is considered as rough (Yin 2021; Di Donna et al. 2016).

The interface direct shear tests were conducted under constant vertical stresses of $50 \mathrm{kPa}, 100 \mathrm{kPa}$ and $150 \mathrm{kPa}$. The shear box was installed in a container that was full of distilled water to ensure the clay samples were saturated during the whole test. The experimental campaign of shearing was divided into two parts: (i) interface direct shear tests of reference, at $13^{\circ} \mathrm{C}$ (constant temperature), (ii) interface direct shear tests after 10 thermal cycles $(\Delta \mathrm{T}$ $=10^{\circ} \mathrm{C}$, i.e., $8^{\circ} \mathrm{C}$ to $18^{\circ} \mathrm{C}$ ). The displacement-controlled shearing test was performed with a rate of $0.006 \mathrm{~mm} / \mathrm{min}$ until a maximum horizontal displacement of $5 \mathrm{~mm}$.

\section{Results}

A constant temperature of $13^{\circ} \mathrm{C}$ was chosen for the reference test as it reflects the soil temperature $5 \mathrm{~m}$ below the ground level in the Paris region (Vasilescu et al. 2018; Vasilescu et al. 2019; Vasilescu 2019). The vertical strain as a function of time and temperature during the 10 thermal cycles is presented in the Figure 1. The results confirm an accumulation of deformations during the

\footnotetext{
* Corresponding author: kexin.yin.research@gmail.com
} 
thermal cycles due to the thermal consolidation process (Di Donna 2014; Idries et al. 2020; Yazdani et al. 2019).
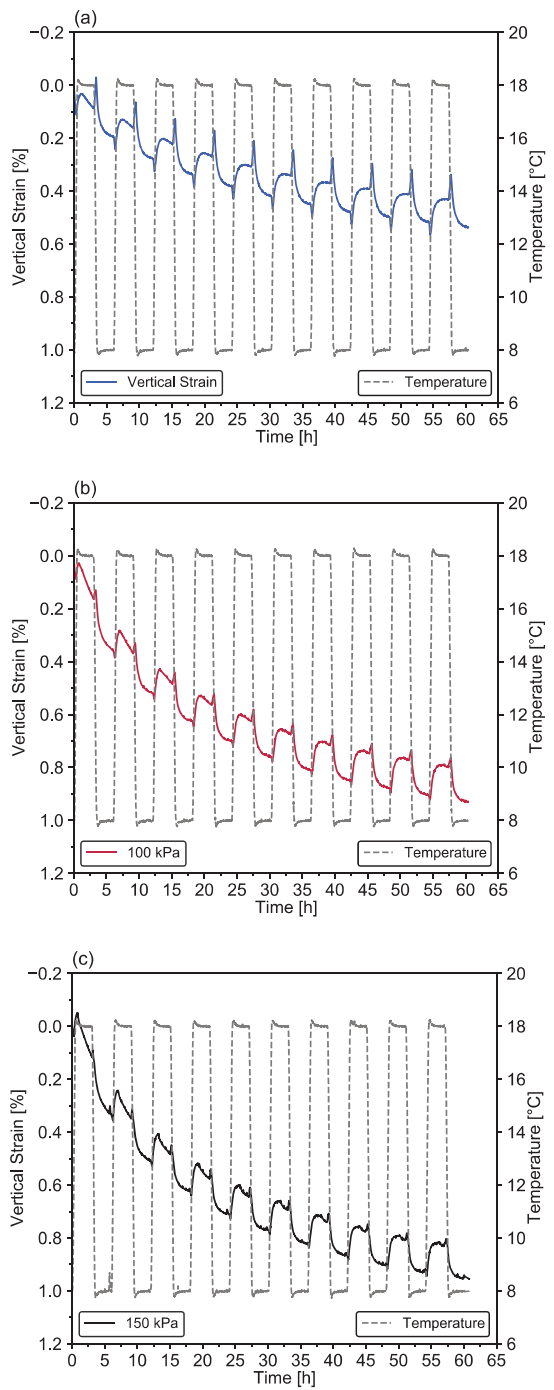

Fig. 1: Vertical strain during 10 thermal cycles: (a) $50 \mathrm{kPa}$; (b) $100 \mathrm{kPa}$; (c) $150 \mathrm{kPa}$.

Figure 2a shows a small increase in shear strength at the normal stress of $50 \mathrm{kPa}$ after the 10 thermal cycles. While at normal stress of 100 and $150 \mathrm{kPa}$, the difference between the reference and the cyclic tests is quite small. The interface friction angle reduces slightly $\left(0.6^{\circ}\right)$ after the 10 cycles, whereas the most significant thermal impact is found to be an increase of $2.6 \mathrm{kPa}$ on the adhesion of the green clay-concrete interface (Figure 2b). This decreasing trend of interface friction angle is not in agreement with the results in Yazdani et al. (2019) and Idries et al. (2020). To conclude, the effect of the thermal consolidation on the shear strength is not so significant, but it increases the contact surface between the green clay and the concrete plate.
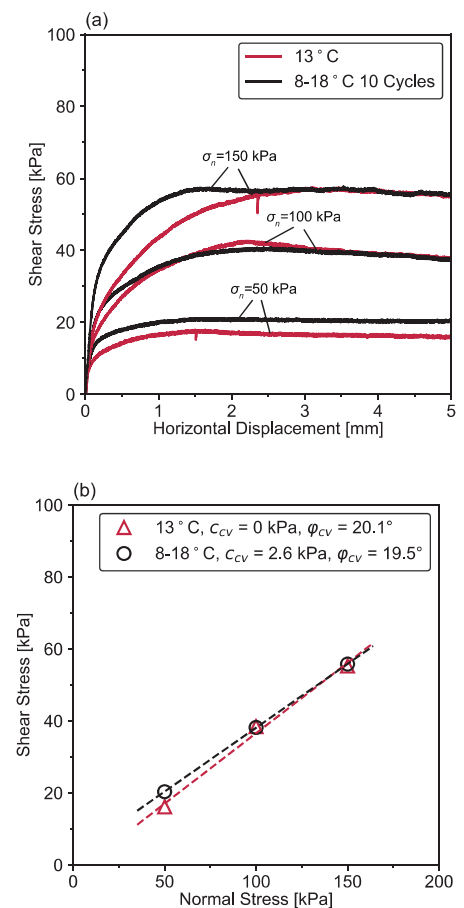

Fig. 2: Shear result comparison between the tests of $13^{\circ} \mathrm{C}$ and 10 thermal cycles: (a) shear stress versus horizontal displacement and (b) interface friction angle.

\section{References}

1. Di Donna, A. (2014). Thermo-Mechanical Aspects of Energy Piles. Ph.D. Thesis. École Polytechnique Fédérale de Lausanne (EPFL), Lausanne, Switzerland.

2. Di Donna, A., Ferrari, A. and Laloui, L. (2016). "Experimental investigations of the soil-concrete interface: physical mechanisms, cyclic mobilization, and behaviour at different temperatures." Canadian Geotechnical Journal 53(4), pp. 659-672.

3. Idries, A., Ghaaowd, I. and Abu-Farsakh, M. (2020). "Effect of one cycle of heating-cooling on the clayconcrete pile interface behavior." Proceedings of the 2nd International Conference on Energy Geotechnics, Apr. 10-13, 2022, La Jolla, California, USA, p. 05012

4. Mantho, A.T. (2005). Exchanges between Soil and Atmosphere Application in the Case of Draught. Ph.D. Thesis. Ecole des Ponts ParisTech, Paris, France

5. Vasilescu, A.-R. (2019). Design and Execution of Energy Piles: Validation by In-Situ and Laboratory Experiments. Ph.D. Thesis. École centrale de Nantes, Nantes, France

6. Vasilescu, A.-R., Fauchille, A.-L., Dano, C., Kotronis, P., Manirakiza, R. and Gotteland, P. (2018). "Impact of temperature cycles at soilconcrete interface for energy piles." Proceedings of the International Symposium on Energy Geotechnics, Sep. 25-28, Lausanne, Switzerland, pp. 35-42. 
7. Vasilescu, R., Yin, K., Fauchille, A.-L., Kotronis, P., Dano, C., Manirakiza, R. and Gotteland, P. (2019). "Influence of thermal cycles on the deformation of soil-pile interface in energy piles." Proceedings of the 7th International Symposium on Deformation Characteristics of Geomaterials, June 26-28, Glasgow, UK, p. 13004.

8. Yazdani, S., Helwany, S. and Olgun, G. (2019). "Influence of temperature on soil-pile interface shear strength." Geomechanics for Energy and the Environment 18, pp. 69-78.

9. Yin, K. (2021). Influence of Clay Fraction on the Mechanical Behavior of a Soil-Concrete Interface. Ph.D. Thesis. École centrale de Nantes, Nantes, France

10. Yin, K., Fauchille, A.-L., Di Filippo, E., Kotronis, P. and Sciarra, G. (2021a). "A review of sand-clay mixture and soil-structure interface direct shear test." Geotechnics 1 (2), pp. 260-306.

11. Yin, K., Liu, J., Lin, J., Vasilescu, A.-R., Othmani, K. and Di Filippo, E. (2021b). "Interface direct shear tests on JEZ-1 Mars regolith simulant." Applied Sciences 11 (15), 7052.

12. Yin, K., Liu, J., Vasilescu, A.-R., Di Filippo, E. and Othmani, K. (2021c). "A procedure to prepare sandclay mixture samples for soil-structure interface direct shear tests." Applied Sciences 11 (12), 5337.

13. Yin, K., Fauchille, A.-L., Othmani, K. Sciarra, G., Kotronis, P., Benoit, Y., Bertrand, F. and Branchu, S. (2019). "Influence of sample preparation on the multi scale structure of sand-clay mixtures." Proceedings of the 7th International Symposium on Deformation Characteristics of Geomaterials, June 26-28, Glasgow, UK, p. 01007.

14. Yin, K., Fauchille, A.-L., Di Filippo, E., Othmani, K., Branchu, S., Sciarra, G. and Kotronis. P. (2021d). "The influence of mixing orders on the microstructure of artificially prepared sand-clay mixtures." Advances in Materials Science and Engineering 2021.

15. Yin, K., Fauchille, A.-L., Kotronis, P. and Sciarra, G. (2020). "Influence of the sample preparation on the multi scale texture of sand clay simplified soils for geotechnical applications - MIP and X-ray Tomography raw data." Mendeley Data, V1, doi: $10.17632 / 6$ vbyfyhd7y.1. 